\title{
Advanced techniques in dobutamine stress echocardiography: focus on myocardial deformation analysis
}

\author{
Emer Joyce, Victoria Delgado, Jeroen J Bax, Nina Ajmone Marsan
}

- Additional references are published online only. To view please visit the journal online (http://dx.doi.org/10.1136/ heartjnl-2013-303850).

Department of Cardiology, Leiden University Medical Center, Leiden,

The Netherlands

\section{Correspondence to}

Dr Emer Joyce, Department of Cardiology, Leiden University Medical Center, Albinusdreef 2, Leiden $2300 \mathrm{RC}$,

The Netherlands;

E.M.Joyce@lumc.nl

Published Online First 23 April 2014

Stress echocardiography is a well validated, cost effective and reliable tool for the diagnosis and assessment of myocardial ischaemia in patients with suspected or known coronary artery disease (CAD). The prognostic value of this technique has been demonstrated in large studies, including diabetic, female, and elderly populations, as well as in patients after myocardial infarction or coronary artery revascularisation. ${ }^{1}$ A related and equally important role of stress echocardiography is the detection of myocardial viability, or reversible dysfunctional myocardium, in patients with CAD and associated left ventricular (LV) systolic dysfunction.

Stress echocardiography may be performed with exercise (bicycle or treadmill) or pharmacological stressors (dobutamine, dipyridamole, and adenosine). Although exercise echocardiography is preferred in many cases owing to the robust prognostic power of exercise capacity, pharmacological stress testing offers the advantage of being able to minimise factors which can significantly degrade exercise image quality (hyperventilation, excessive chest wall movement) and thus lower diagnostic accuracy, in addition to being an alternative for patients who cannot exercise. Dobutamine is a widely available sympathomimetic agent that at high doses acts similarly to exercise in increasing myocardial oxygen demand, thereby precipitating ischaemia in the presence of a flow limiting coronary artery stenosis. Given the large body of evidence available for this technique, and the fact that vasodilator stress testing does not consistently produce wall thickening abnormalities even in the presence of a significantly flow limiting stenosis, ${ }^{2}$ this article will focus on dobutamine stress echocardiography (DSE).

The hallmark of induced ischaemia on DSE is the development of a new or worsening regional wall motion abnormality. At low dose, dobutamine increases myocardial perfusion-and thus myocardial contractility - if sufficient myocardial contractile reserve is present. The development of augmented myocardial contractility at low dose in segments with resting dysfunction (with subsequent deterioration at peak doses if performed-the so-called 'biphasic response') is indicative of viability. Compared to perfusion imaging, DSE has similar sensitivity but higher specificity, ${ }^{\mathrm{w} 1}$ contributing to its cost effectiveness, and additionally avoids the need for ionising radiation-both increasingly important concerns in this modern era of an ever expanding menu of non-invasive imaging strategies.

\section{Learning objectives}

- Cardiac resynchronization therapy (CRT) is an established treatment for heart failure patients. However, there remain subpopulations that were underrepresented in randomised controlled trials and for which the benefits of this therapy is less clear.

- The present review article summarises the evidence on the effects of CRT in specific heart failure subpopulations such as patients with mild heart failure symptoms, non-left bundle branch block morphology of the QRS complex, diabetics or renal failure patients.

- Based on current literature, dedicated randomised controlled trials in these subpopulations are needed to further determine which patients may benefit from CRT.

However, potential limitations surrounding image quality, dependence on expert observers, and lack of quantitation may challenge the diagnostic accuracy of DSE. In parallel, interest is growing in highly sensitive imaging techniques that may be able to target the ischaemic cascade at an earlier stage than that represented by an induced wall motion abnormality. The aim of the current article is thus to summarise both established and emerging advanced techniques to improve the accuracy of stress echocardiography in its main roles of ischaemia detection and viability assessment-specifically, improved visualisation through use of contrast for LV opacification, and the main focus, quantitative analysis using myocardial deformation analysis.

\section{DSE WITH CONTRAST: IMPROVED \\ VISUALISATION}

Adequate endocardial border visualisation is essential to decrease inter-observer variability and improve the diagnostic accuracy of stress echocardiography. Although use of second harmonic imaging has been shown to improve inter-observer agreement and accuracy, ${ }^{\mathrm{w} 2}$ stress echocardiography interpretation may still be limited in patients with poor acoustic windows such as those with increased body mass index or obstructive lung disease. The development of intravenous contrast agents that can cross the pulmonary vascular bed and thus 


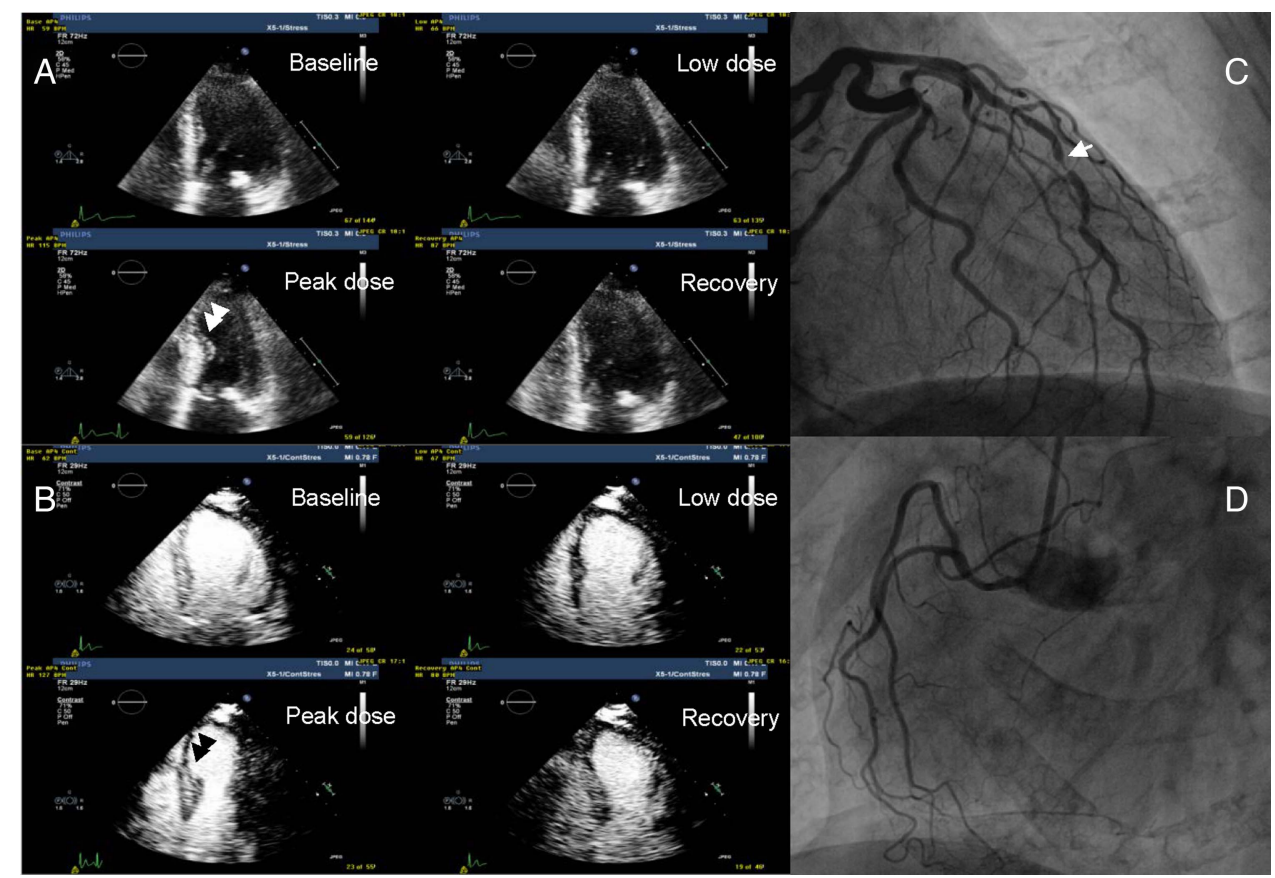

Figure 1 Dobutamine stress echocardiography with contrast of an 80-year-old woman with chest pain complaints. Panels A and B show respectively non-contrast and contrast enhanced LV apical four-chamber views at baseline, low dose, peak dose, and recovery acquisitions. At peak dose dobutamine, on contrast enhanced LV apical four-chamber view, the apical segments become hypo-akinetic (arrows). These new wall motion abnormalities are not well visualised on non-contrast enhanced images (arrows). Panels C and D show the invasive coronary angiography, demonstrating a subtotal occlusion of the left anterior descending coronary artery (arrow) and a right coronary artery without significant lesions.

provide LV opacification has led to improved assessment of ventricular chamber dimensions and global and regional systolic function in these patients (figure 1). ${ }^{\mathrm{w} 3}$ The clinical benefit of enhanced endocardial border detection using contrast administration in DSE previously suggested in single centre studies $^{\mathrm{w} 4} \mathrm{w}^{\mathrm{w}}$ has recently been confirmed in a randomised trial. ${ }^{3}$ In an unselected population of 101 patients undergoing both non-contrast and contrast enhanced studies, the use of contrast enhanced studies showed significantly improved endocardial visualisation at both rest and peak stress, leading to both a higher confidence of interpretation and greater diagnostic accuracy as compared with angiography $(66 \%$ vs $53 \%, \mathrm{p}=0.02)$. The highest impact on DSE accuracy with contrast enhancement was seen in the patients with the poorest image quality. ${ }^{3}$

Current guidelines recommend a combination of second harmonic imaging with contrast opacification in the absence of optimal image quality, defined as poor visualisation of $\geq 2$ segments. ${ }^{14} 5$ Previous concerns regarding the possible

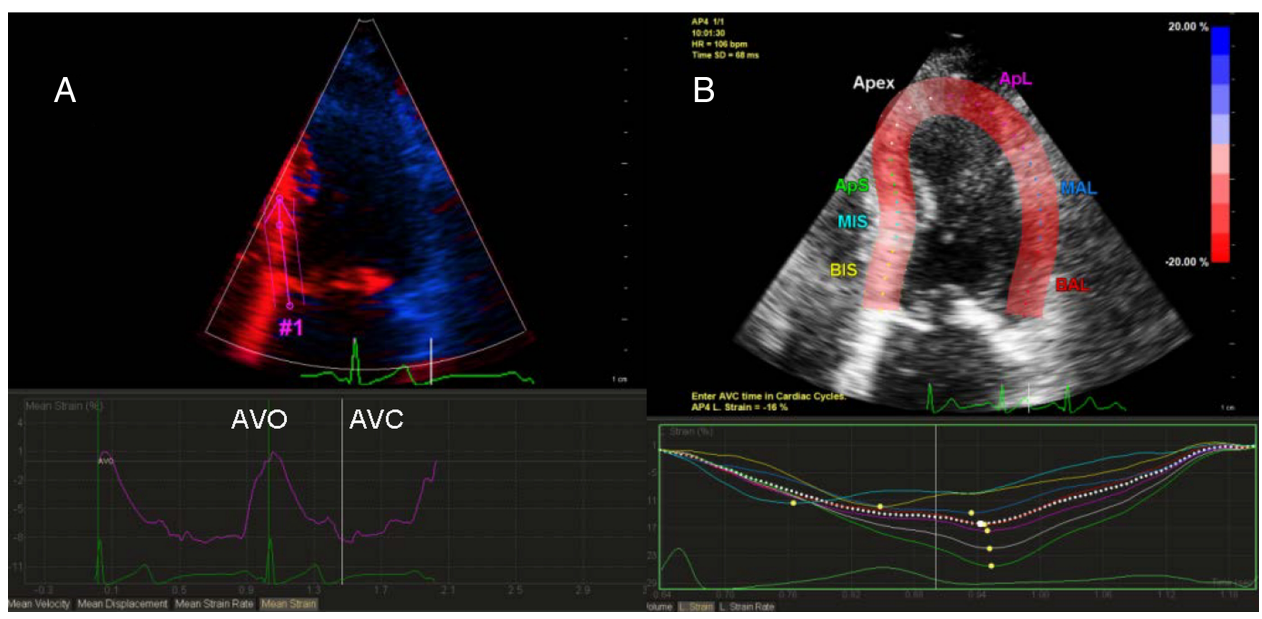

Figure 2 Tissue Doppler imaging (TDI) and speckle tracking echocardiography (STE) derived strain imaging. From TDI derived strain, the region of interest is selected and the time-strain curve is displayed showing a peak systolic longitudinal strain of $-8 \%$ (A). The aortic valve opening (AVO) and closure (AVC) are indicated. From STE derived strain, the region of interest includes the six segments of the LV apical four-chamber view and the time-strain curves are displayed for each segment (Apex; ApL, apical lateral; ApS, apical septal; BAL, basal anterolateral; BIS, basal inferoseptal; MAL, mid anterolateral; MIS, mid inferoseptal). 
Box 1 Tissue Doppler imaging (TDI) dobutamine stress

echocardiography (DSE) data acquisition and analysis

- TDI derived strain imaging used as an adjunct to DSE:

- High temporal resolution (required at peak dose) assessment of site specific strain

- Feasible: only $2 \%$ of segments should be excluded because $>30^{\circ}$ angle of insonation

Limitations:

Strain and strain rate data in one dimension

Angle dependent: the tissue deformation direction should be aligned

parallel with the Doppler beam direction (challenging in apical segments)

- TDI derived strain data acquisition during DSE:

- Acquisition should be performed at rest, low dose, and peak dose

- Acquisition settings: harmonic imaging, narrow the imaging sector to improve visual assessment of signal quality, reduce signal noise and optimise temporal and spatial resolution. A frame rate of $100 \mathrm{frames} / \mathrm{s}$ or more is recommended.

- TDI derived strain data analysis:

- Use of an offset distance of $12 \mathrm{~mm}, 40 \mathrm{~ms}$ Gaussian filter and manual or automatic tracking of the region of interest in each frame

- Parameters to assess:

Peak systolic strain rate $(1 / \mathrm{s})$

Peak systolic and end-systolic strain (\%)

Post-systolic shortening (\%)

Post-systolic index (post-systolic shortening/peak systolic strain)

- Time for analysis: analysis of TDI derived strain in all segments takes $\sim 25 \mathrm{~min}$ association of ultrasonic contrast agents (either perflutren based such as Definity (Lantheus Medical Imaging; N. Billerica, Massachusetts, USA) or sulphur hexafluoride based such as Sonovue (Bracco, Milan, Italy)) with serious adverse cardiopulmonary reactions have now largely abated following cumulative evidence from large single and multicentre studies and a subsequent meta-analysis confirming their safety. ${ }^{\text {w5-w9 }}$ Specifically, use of these agents has not been associated with a greater incidence of mortality, acute myocardial infarction or other serious adverse events in patients undergoing rest and/or stress echocardiography. However, caution is still recommended in critically ill patients due to the potential for serious allergic reactions; of note, Sonovue remains contraindicated in the first week after an acute coronary syndrome. ${ }^{5}$

\section{QUANTITATIVE ANALYSIS}

Deformation analysis: principles and techniques

The assessment of regional function by standard two dimensional (2D) echocardiography is highly subjective and strongly dependent on sufficient image quality. Additional challenges specific to stress echocardiography include the need to integrate wall thickening as well as excursion and to compare multiple segments (including those outside of the current view) simultaneously, as well as the ability to distinguish true motion from translational motion. Changes in regional myocardial performance during DSE may be more accurately assessed using quantitative parameters including myocardial velocity and deformation imaging, which overcome many of these challenges.

Myocardial velocity imaging detects motion rather than myocardial wall deformation and therefore may be influenced by overall heart motion, cardiac rotation, and motion induced by tethering from adjacent segments. Conversely, local deformation indices such as tissue Doppler imaging (TDI) derived strain and strain rate imaging, and more recently speckle tracking echocardiography (STE) derived strain parameters, represent a highly sensitive method of quantifying regional myocardial function by measuring the magnitude of myofibre contraction and relaxation (figure 2). Characteristics of TDI and STE derived strain data acquisition and analysis are summarised in boxes 1 and 2. Specifically, strain represents the percentage change in length of a myocardial fibre relative to its original dimension, with strain rate $(1 / \mathrm{s})$ representing its temporal derivative. ${ }^{\mathrm{w} 10}$ Both are less susceptible to translational motion and/or tethering and are homogenously distributed from base to apex, thus providing evaluation of the active component of myocardial deformation or contractility. The spatial orientation of the myofibres in the endocardium, mid-myocardial layer and epicardium leads to a characteristic multidirectional deformation of the left ventricle-shortening in the longitudinal and circumferential directions, and thickening in the radial direction. STE allows assessment of deformation in all three directions and quantification of rotational mechanics (twist/torsion),
- Time for analysis: analysis of speckle tracking derived strain in all segments takes $\sim 25 \mathrm{~min}$. Recently developed quantification software allows for a more rapid analysis 


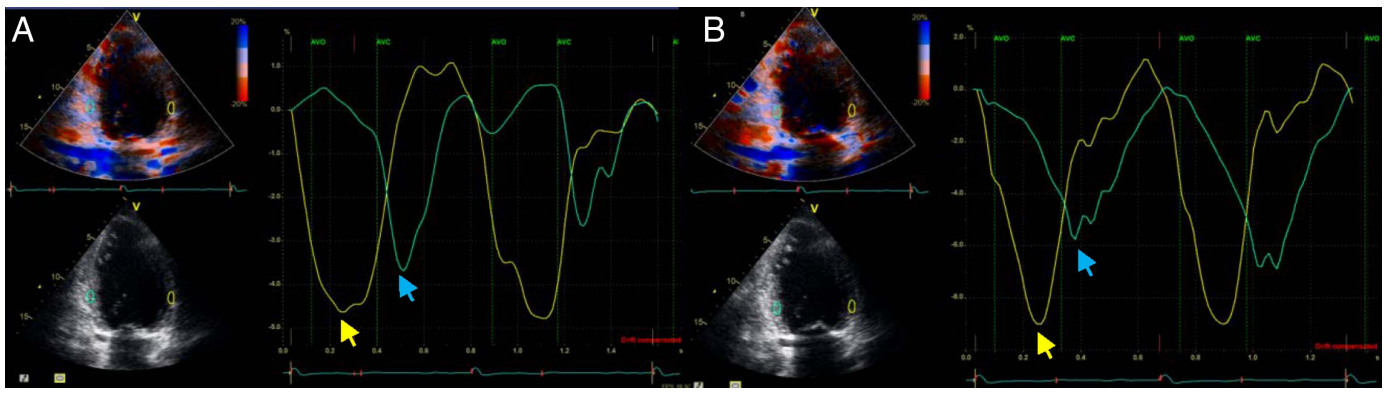

Figure 3 Post-systolic shortening. Example of patient with three-vessel coronary artery disease, left ventricular ejection fraction 35\%, and hypokinesia inferoposterolateral. (A) At rest, tissue Doppler imaging (TDI) derived strain curves show impaired peak systolic strain of the anterior wall (yellow arrow $-4.5 \%$ ) and post-systolic shortening of the inferior wall (blue arrow $-3.7 \%$ ). (B) At low dose dobutamine stress echocardiography, there is an improvement of peak systolic strain of the anterior wall (yellow arrow -7\%) and the post-systolic shortening of the inferior wall increases (blue arrow $-6 \%$ ).

reflecting the twisting motion from apex to base accompanying deformation that ensures the equal distribution of regional stresses across the myocardial wall. In addition, deformation parameters from both modalities allow assessment of the time course of myocardial thickening as well as its extent, thereby providing a more intrinsic characterisation of regional (and ultimately global) LV function.

An increasingly relevant timing based parameter that can be derived from these techniques is postsystolic shortening (PSS), which reflects thickening of the myocardium occurring after aortic valve closure (figure 3). ${ }^{6}$ Criteria to define pathologic PSS include: transient PSS (occurring during and resolving after ischaemia), the presence of decreased systolic function (peak systolic strain $>-7 \%$ ) or, in case of moderately reduced systolic function $(-7 \%>$ peak systolic strain $>-18 \%)$, the presence of PSS $>20 \%$ of peak strain or PSS that occurs $>90 \mathrm{~ms}$ after aortic valve closure. ${ }^{\text {w11 }}$ Therefore, a reliable definition of aortic valve opening and closure is pivotal to assess PSS. Several modalities have been proposed to define these event timings. Using colour coded TDI, the anatomic colour coded TDI M mode aligned across the mitral valve leaflet shows a thin blue line

Table 1 Summary of longitudinal deformation characteristics at rest and during dobutamine stress for each ischaemic substrate

\begin{tabular}{|c|c|c|c|c|c|c|c|c|c|}
\hline & \multicolumn{3}{|l|}{ Rest } & \multicolumn{6}{|c|}{ Dobutamine stress } \\
\hline & \multirow[b]{2}{*}{ PSSR } & \multirow[b]{2}{*}{ SS } & \multirow[b]{2}{*}{ PSS } & \multicolumn{3}{|c|}{ Low dose } & \multicolumn{3}{|c|}{ Peak dose } \\
\hline & & & & PSSR & SS & PSS & PSSR & SS & PSS \\
\hline Control & $\mathrm{N}$ & $\mathrm{N}$ & 0 * & $\nearrow$ & $\nearrow$ & 0 & $\nearrow \nearrow$ & $\bigwedge$ & 0 \\
\hline Acute ischaemia & $\downarrow$ & $\downarrow$ & $\uparrow$ & $\searrow$ & $\searrow$ & $\nearrow$ & $\searrow \searrow$ & $\searrow \searrow$ & 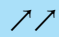 \\
\hline Stunning & $\downarrow$ & $\downarrow$ & $\uparrow$ & $\nearrow$ & $\nearrow$ & $\searrow$ & 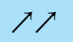 & $\bigwedge$ & 0 \\
\hline Chronic ischaemia/hibernation & $\downarrow$ & $\downarrow$ & $\uparrow$ & $\nearrow$ & $\nearrow$ & $\nearrow$ & $\searrow$ & $\searrow$ & $\nearrow \nearrow$ \\
\hline Non-transmural infarction & $\downarrow \downarrow$ & $\downarrow \downarrow$ & $\uparrow$ & $\searrow$ & $\searrow$ & $\nearrow$ & $\searrow \searrow$ & $\searrow \searrow$ & $\nearrow \nearrow$ \\
\hline Transmural infarction & 0 & 0 & 0 & $\rightarrow$ & $\rightarrow$ & $\rightarrow$ & $\rightarrow$ & $\rightarrow$ & $\rightarrow$ \\
\hline
\end{tabular}

during end-systole and early diastole, the beginning of which indicates the aortic valve closure and opening, respectively. ${ }^{\text {w11 }}$ With 2D speckle tracking echocardiography, the analysis should start with the $\mathrm{LV}$ apical long axis view where the aortic valve closure can be visualised. The software will automatically use that timing to define the aortic valve closure in the apical two- and four-chamber views. All of these parameters (alone or in combination) have already been studied extensively for both detection of acute or chronic ischaemia and prediction of regional myocardial recovery or viability.

\section{Detection of CAD and ischaemia}

Ischaemia is traditionally defined on stress echocardiography as a regional reduction of myocardial thickening or inward motion of the endocardial border, a reflection of the radial function of the myocardium, and detectable in the ischaemic cascade before electrocardiographic changes and symptoms. ${ }^{\text {w12 }}$ However, ischaemia induced myocardial changes begin in the subendocardial layer, with the first component of the ischaemic cascade being flow heterogeneity between the myofibre layers. $^{\text {w13 }}$ Given that longitudinal function is largely determined by subendocardial fibres, longitudinal deformation parameters (strain and strain rate) rather than radial function parameters may be superior for earlier ischaemia detection on DSE. Furthermore, given that ischaemia not only decreases the amplitude of contraction but also slows its onset and velocity as well as delaying the onset of relaxation, deformation analysis provides the additional advantage of being able to assess the timing parameters of systolic shortening, in addition to its reduced amplitude. PSS in particular is an extremely sensitive and very early marker of acute ischaemia and is thought to directly reflect reduced subendocardial blood flow. ${ }^{6}$ Table 1 summarises the response of (longitudinal) deformation parameters-strain, strain rate, and PSS-at rest and during both low and peak dose DSE. ${ }^{7}$ While in normal tissue challenged with dobutamine, deformation will increase (linear increase in strain rate and increase in strain until LV filling and thus stroke volume is reduced by increasing heart rate), in 
Table 2 Clinical studies evaluating deformation parameters during DSE for detection of ischaemia and/or presence of CAD

\begin{tabular}{|c|c|c|c|c|c|c|c|}
\hline Author & $\begin{array}{l}\text { No. of } \\
\text { subjects }\end{array}$ & $\begin{array}{l}\text { Method of } \\
\text { deformation } \\
\text { analysis }\end{array}$ & Patient characteristics & $\begin{array}{l}\text { Confirmation of } \\
\text { ischaemia/CAD }\end{array}$ & Parameters & Ischaemic response* & Predictive valuet \\
\hline Voigt et al ${ }^{8}$ & 44 & TDI & Known or suspected CAD & $\begin{array}{l}\text { SPECT and coronary } \\
\text { angiogram (on } \\
\text { angiography, CAD defined } \\
\text { as }>50 \% \text { diameter } \\
\text { stenosis) }\end{array}$ & $\begin{array}{l}\text { SS (peak and ejection time), } \\
\text { PSSR, PSS, PSI, timing } \\
\text { parameters }\end{array}$ & $\begin{array}{l}\text { \PSSR increase, } \downarrow \text { SS, PSS } 100 \% \text { (ischaemic) vs } \\
47 \% \text { (non-ischaemic), } \uparrow \text { timing parameters }\end{array}$ & $\begin{array}{l}\text { Sensitivity and specificity } 86 \% \text { and } \\
95 \% \text { vs } 81 \% \text { and } 82 \% \text { for WMS } \\
\text { assessment; AUC for PSI 0.90, PSI } \\
\text { cut-off }>35 \%, 82 \% \text { sensitivity and } \\
85 \% \text { specificity }\end{array}$ \\
\hline $\begin{array}{l}\text { Weidemann } \\
\text { et } a l^{12}\end{array}$ & 30 & TDI & $\begin{array}{l}\text { Known intermediate stenosis in a } \\
\text { large coronary artery, without } \\
\text { other CAD }\end{array}$ & $\begin{array}{l}\text { Coronary angiography+ } \\
\text { FFR (ischaemic group } \\
\text { defined as FFR }<0.75 \text { ) }\end{array}$ & $\begin{array}{l}\text { PSSR, SS (peak and } \\
\text { end-systolic), PSS }\end{array}$ & $\begin{array}{l}\text { In the target region, } \uparrow \text { PSSR in the } \\
\text { non-ischaemic group but no } \uparrow \text { in the ischaemic } \\
\text { group; } \downarrow S S \text { in the ischaemic group vs no } \\
\text { change in the non-ischaemic group; } \uparrow \uparrow P S S \text { in } \\
\text { the ischaemic group vs } \uparrow \text { in non-ischaemic } \\
\text { group }\end{array}$ & $\begin{array}{l}\text { On ROC curve analysis the change } \\
\text { in strain rate from rest to peak } \\
\text { was the best parameter to detect } \\
\text { ischaemia: AUC } 0.90 \text {, sensitivity } \\
89 \% \text { and specificity } 86 \%\end{array}$ \\
\hline Ingul et $\left.a\right|^{9}$ & 197 & $\begin{array}{l}\text { TDI } \\
\text { STE }\end{array}$ & $\begin{array}{l}\mathrm{N}=76 \mathrm{CAD} \\
\mathrm{N}=61 \text { no } \mathrm{CAD} \\
\mathrm{N}=60 \text { low risk } \mathrm{CAD}\end{array}$ & $\begin{array}{l}\text { Coronary angiography } \\
(\mathrm{N}=136)(\mathrm{CAD} \geq 50 \% \\
\text { diameter stenosis) }\end{array}$ & $\begin{array}{l}\text { PSSR, SS (end-systolic), PSS, } \\
\text { PSI, timing parameters }\end{array}$ & $\begin{array}{l}\text { PSSR significantly } \downarrow \text { in segments at risk versus } \\
\text { normal segments, } p<0.001\end{array}$ & $\begin{array}{l}\text { AUC PSSR } 0.90 \text { (both TDI+STE) } \\
\text { AUC SS } 0.87 \text { (both TDI+STE) } \\
\text { AUC PSI } 0.86 \text { (TDI) and } 0.75 \text { (STE) } \\
\text { Sensitivity of PSSR using both TDI } \\
(87 \%) \text { and STE ( } 84 \%)>\text { WMS } \\
(75 \%), p=0.02 \text { and } 0.03 \text {, } \\
\text { respectively }\end{array}$ \\
\hline $\begin{array}{l}\text { Hanekom } \\
\text { et } a l^{11}\end{array}$ & 150 & $\begin{array}{l}\text { TDI } \\
\text { STE } \\
\text { Sentinel segment } \\
\text { approach }\end{array}$ & $\begin{array}{l}\text { Clinically indicated DSE for } \\
\text { evaluation of ischaemia (excluded } \\
\text { severely depressed LVEF, LBBB, } \\
\text { previous CABG, significant } \\
\text { valvular heart disease) }\end{array}$ & $\begin{array}{l}\text { Coronary angiography } \\
\text { (CAD } \geq 70 \% \text { diameter } \\
\text { stenosis) }\end{array}$ & $\begin{array}{l}\text { PSSR, SS (end-systolic), PSS, } \\
\text { PSI, delta SR (value at peak } \\
\text { stress-value at baseline) }\end{array}$ & $\begin{array}{l}\downarrow P S S R \text {, delta } S R+S S \text { in those with significant } \\
\text { CAD vs those without } C A D(p<0.0001) \\
\uparrow P S I \text { in those with significant } C A D \text { vs those } \\
\text { without } C A D \text { ( } p<0.0001)\end{array}$ & $\begin{array}{l}\text { AUC PSSR } 0.71 \text { (TDI) and } 0.67 \\
\text { (STE) } \\
\text { Accuracy of WMS }(75 \%) \text { vs PSSR } \\
\text { by TDI (74\%) and STE }(69 \%) \text { were } \\
\text { similar } \\
\text { Accuracy of PSSR by TDI+STE was } \\
\text { similar for LAD (79\% vs } 78 \% \text { ) and } \\
\text { LCx }(73 \% \text { vs } 67 \%) \text { territories but } \\
\text { lower for STE in RCA territory } \\
\text { (74\% vs } 59 \%, p=0.008 \text { ) }\end{array}$ \\
\hline $\mathrm{Ng}$ et $a l^{10}$ & 102 & STE & $\begin{array}{l}\text { Clinically indicated DSE for } \\
\text { evaluation of ischaemia }\end{array}$ & $\begin{array}{l}\text { Coronary angiography } \\
\text { (CAD } \geq 50 \% \text { diameter } \\
\text { stenosis) }\end{array}$ & $\begin{array}{l}\text { Global longitudinal peak } \\
\text { systolic strain (GLS), global } \\
\text { circumferential strain (GCS), } \\
\text { and global radial strain (GRS) }\end{array}$ & $\begin{array}{l}\text { All } 3 \text { orthogonal strains significantly } \downarrow \text { at peak } \\
\text { stress in patients with CAD }\end{array}$ & $\begin{array}{l}\text { Sensitivities for GLS, GCS, GRS, } \\
\text { and WMSI were } 84.2 \%, 73.9 \% \text {, } \\
78.3 \% \text {, and } 76 \% \text { respectively } \\
\text { GLS and WMSI had comparable } \\
\text { accuracy }(85.2 \% \text { vs } 82.1 \% \text {, } \\
p=0.70) \text { while accuracies of GCS } \\
(75.7 \%) \text { and GRS }(70.3 \%) \text { were } \\
\text { lower } \\
\text { Combination of GLS + WMSI had } \\
\text { highest sensitivity }(100 \%) \text { and } \\
\text { accuracy }(96.3 \%)\end{array}$ \\
\hline Yu et $a l^{13}$ & 76 & STE & $\begin{array}{l}\mathrm{N}=34 \text { patients with severe } \\
3 \text {-vessel } C A D+\text { preserved LVEF } \\
\mathrm{N}=42 \text { controls }\end{array}$ & $\begin{array}{l}\text { Coronary angiography } \\
\text { (CAD } \geq 70 \% \text { diameter } \\
\text { stenosis in } 3 \text { vessels) }\end{array}$ & $\begin{array}{l}\text { Global and segmental } \\
\text { longitudinal strain (SS), PSSR, } \\
\text { circumferential strain and } \\
\text { strain rate (CSS, CSR), timing } \\
\text { parameters }\end{array}$ & $\begin{array}{l}\text { Patients with CAD vs controls showed } \\
\text { significantly } \downarrow S S \text {, PSSR, CSS and CSR at both } \\
\text { low and peak doses }\end{array}$ & $\begin{array}{l}\text { On multivariate analysis, global } \\
\text { PSSR at low dose was an } \\
\text { independent predictor of } \\
\text { multivessel CAD (OR 1.63, } 95 \% \mathrm{CI} \\
1.12 \text { to } 2.82 \text { ) }\end{array}$ \\
\hline
\end{tabular}

*Indicates response of parameters at peak-dose stress unless indicated.
tIndicates predictive value of peak dose stress parameters unless indicated.

AUC, area under the curve; CAD, coronary artery disease; DSE, dobutamine stress echocardiography; FFR, fractional flow reserve; LAD, left anterior descending artery; LBBB, left bundle branch block; LCX, left circumflex artery; RCA, right coronary artery; ROC, receiver operating characteristics curve; PSI, post-systolic shortening index; PSS, post-systolic strain; PSSR, peak systolic strain rate; SPECT, single photon emission CT; SS, systolic strain; STE, speckle tracking echocardiography; TDI, tissue Doppler imaging; WMS, wall motion scoring; WMSI, wall motion score index. 
acutely ischaemic tissue the systolic component of deformation will reduce linearly while the postsystolic component will increase. ${ }^{7}$

Evidence from clinical studies investigating the diagnostic accuracy of these quantitative techniques for detection of ischaemia either alone or in combination with expert wall motion analysis is growing. Table 2 shows the clinical studies evaluating both the magnitude and timing deformation parameters obtained using TDI or STE (or both) during DSE for detection of ischaemia and/or presence of CAD.$^{8-13}$ A clinical study by Voigt et $a l^{8}$ clearly illustrated the value of strain indexes to differentiate acutely ischaemic segments from normal myocardium. In 44 patients undergoing DSE for investigation of known or suspected CAD, using simultaneous myocardial perfusion nuclear imaging to define regional acute ischaemia, the feasibility and accuracy of TDI longitudinal strain and strain rate parameters in identifying inducible ischaemia was assessed. Strain and strain rate increase was reduced in ischaemic segments and PSS was found in $100 \%$ of the ischaemic segments versus $47 \%$ of the non-ischaemic segments at peak stress. Interestingly, post-systolic shortening index (PSI)the ratio of PSS to maximal shortening-was the best parameter to identify stress induced ischaemia (sensitivity $82 \%$ and specificity $85 \%$, area under the curve (AUC) 0.90) (table 2). ${ }^{8}$
More recently, several studies have also tested the diagnostic value of STE deformation parameters for both CAD and ischaemia detection (figure 4). In a relatively large study of 197 patients undergoing DSE, automated myocardial deformation analysis using STE was found to be both feasible and accurate, enhancing sensitivity in the hands of expert observers. ${ }^{9}$ Specifically, sensitivity of STE longitudinal strain rate $(84 \%$ vs $75 \%, p=0.03)$ and endsystolic strain $(88 \%$ vs $75 \%, p=0.02)$ was superior to wall motion scoring for the detection of CAD in 136 patients who underwent coronary angiography (table 2). ${ }^{9}$ The comparative accuracies of the three orthogonal myocardial strains for ischaemia detection during DSE was recently studied in a multicentre clinical study by $\mathrm{Ng}$ et al. $^{10}$ Providing clinical evidence of known pathophysiological concepts as discussed earlier, sensitivity, specificity, and accuracy of peak stress longitudinal strain was found to be superior to both circumferential or radial strain for the detection of significant CAD in 102 patients undergoing clinically indicated DSE for evaluation of ischaemia and subsequent diagnostic coronary angiography. Furthermore, quantitative longitudinal strain analysis was found to be as accurate as expert wall motion analysis and to provide incremental diagnostic accuracy in combination with expert wall motion analysis for detection of significant CAD (table 2). ${ }^{10}$

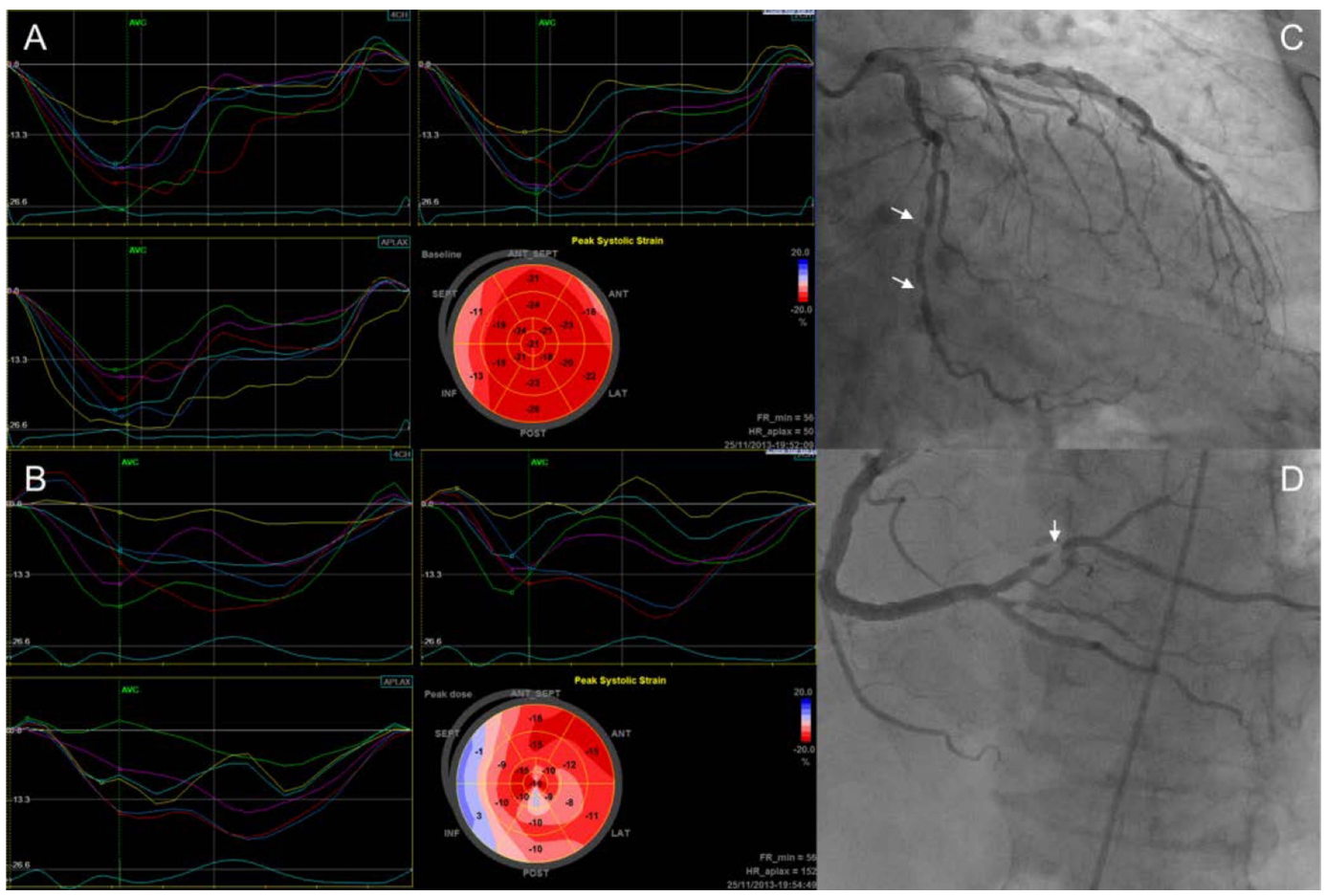

Figure 4 Diagnosis of myocardial ischaemia with dobutamine stress speckle tracking echocardiography (STE) strain imaging. (A) At rest, the time-longitudinal strain curves of the apical four-, two- and three-chamber views are displayed showing preserved longitudinal strain in all segments but impaired in the basal inferoseptal segments. The bull's eye plot (normal strain values represented in red, reduced strain values in lighter shades of red, and absence of systolic deformation depicted in blue) provides the segmental and global values of longitudinal strain (-20.1\%). (B) At peak stress, there is a global impairment of LV longitudinal strain $(-9.9 \%)$ with a significant reduction in the basal and mid inferoseptal segments and in the posterobasal and mid lateral segments. The invasive coronary angiography shows significant stenosis in the mid circumflex coronary artery (C) and in the posterolateral branch (D). 
Increased feasibility of applying deformation techniques to DSE has also been suggested by adopting a sentinel, or representative, segment approach, as demonstrated in a study by Hanekom et $a l^{11}$ comparing STE and TDI derived longitudinal deformation parameters in 150 patients undergoing DSE and subsequent coronary angiography. Using these segments only (apical septum for the left anterior descending (LAD) coronary artery, basal posterior for the left circumflex coronary artery, and mid inferior for the right coronary artery (RCA)), diagnostic accuracies of both methods were compared, and found to be similar in the LAD territory. However, the diagnostic accuracies were lower for STE strain in the RCA territory, most likely due to greater dependence of the latter technique on image quality in these territories. The possible use of this sentinel segment approach, together with the angle independency, semi-automated and evolving user friendly nature of STE, represent an important advance in helping to identify ischaemic abnormalities on DSE invisible to the human eye. Given that for any given coronary stenosis the prognostic benefit of recanalisation is much higher if ischaemia is demonstrated, additional techniques that can accurately unveil this ischaemic response at an earlier stage have significant potential to provide better risk stratification in specific patient populations.

\section{Detection of viability}

The prognostic value of DSE for the identification of dysfunctional myocardium that is viable and therefore has the potential for recovery of function is undisputed. ${ }^{\text {w14 }}$ The hallmark of viability assessment with DSE is the identification of contractile reserve, defined as resting myocardial dysfunction that recruits in response to inotropic stimulation with dobutamine. The biphasic response-increased contractility in resting dysfunctional myocardium at low dose but deterioration of contractility at peak doses as demand/supply mismatch leads to ischaemia-is the most specific finding. However, the assessment of myocardial viability based on wall motion scoring during stress echocardiography is subjective and highly operator dependent. ${ }^{\text {w15 }}$ In addition, assessment of changes in motion in regional walls with already pre-existing abnormalities adds a further layer of complexity to conventional wall motion interpretation. Therefore, quantitative assessment of contractile reserve using analysis of deformation parameters may be particularly attractive in providing an accurate estimation of this important prognostic endpoint.

As illustrated in table 1 , deformation parameters follow typical patterns at baseline and in response to low and peak doses of dobutamine, according to the particular ischaemic/LV dysfunction substrate, not only in acute but also in chronic ischaemia. Specifically regarding substrates associated with viability on DSE, stunning (reversible segmental myocardial dysfunction in the setting of normal myocardial perfusion) is associated with decreased strain and strain rate at rest, and the presence of
PSS. But during dobutamine, systolic deformation is restored to almost normal and PSS disappears by peak dose. Conversely, hibernating myocardium (reversible segmental dysfunction related to sustained hypoperfusion and/or repetitive episodes of ischaemia) or chronic ischaemia with a residual critical stenosis may show a small initial increase in strain rate/strain with dobutamine followed by a decrease at higher doses, and increased PSS throughout. ${ }^{7}$ Quantitative analysis may also permit differentiation of non-transmural from transmural infarction. While chronic non-transmural infarction may show a decrease in strain and strain rate with some PSS, transmural infarction shows no deformation, systolic or post-systolic, at rest or during dobutamine or even dyskinesia and lengthening/ thinning during peak dose dobutamine. ${ }^{7}$ w16

Similarly, as in the case of ischaemia detection, consideration of LV myofibre sublayer mechanics may also further highlight the role of deformation in quantitative viability assessment. Given that longitudinal strain is governed by the subendocardium, it will be reduced in the presence of a subendocardial perfusion deficit, while other strain components (particularly circumferential strain), largely controlled by subepicardial layer mechanics, may remain unaltered. However, a larger and/or transmural infarction leads to reduction in multidirectional strain (as well as rotation parameters, including LV torsion). Thus, in addition to the use of longitudinal deformation parameters to identify specific ischaemic substrates, layer specific strain (and torsion) analysis may allow accurate discrimination between different transmurality categories of myocardial infarction. ${ }^{14}$ More specifically, in dysfunctional ischaemic myocardium associated with reduced subendocardial function, viability may arise due to preserved (mid and) subepicardial layer function.

An increasing body of clinical evidence has demonstrated the ability of DSE strain parameters (rest and low dose stages) to identify viability in association with or independent of conventional wall motion assessment. Table 3 illustrates clinical studies evaluating deformation parameters during DSE for the assessment of viability. ${ }^{15-19}$ Longitudinal strain and strain rate imaging evaluated at low dose have shown particular promise in the identification of viability, as defined by the gold standard of functional recovery after revascularisation. Hanekom et $a l^{15}$ investigated TDI derived strain and strain rate in 55 patients with previous myocardial infarction and LV dysfunction undergoing DSE for viability assessment (figure 5). While the sensitivity and specificity of multiple tested parameters were not significantly better than wall motion scoring alone, the combination of wall motion scoring and low dose strain rate imaging provided incremental value to wall motion alone for the prediction of viability (sensitivity was augmented from $73 \%$ to $82 \%$, although specificities were comparable).

More recently, using both TDI and STE derived parameters (in all three orthogonal directions) for 
Table 3 Clinical studies evaluating deformation parameters during DSE for the assessment of viability

\begin{tabular}{|c|c|c|c|c|c|c|c|}
\hline Author & $\begin{array}{l}\text { No. of } \\
\text { patients }\end{array}$ & $\begin{array}{l}\text { Method of } \\
\text { deformation } \\
\text { analysis }\end{array}$ & Patient characteristics & Definition of viability & Parameters & $\begin{array}{l}\text { Viability } \pm \text { scar } \\
\text { response* }\end{array}$ & Predictive valuet \\
\hline Hoffmann et al ${ }^{17}$ & 37 & TDI & $\begin{array}{l}\text { Previous myocardial infarction } \\
\text { with reduced LVEF (mean LVEF } \\
44 \pm 10 \% \text { ) }\end{array}$ & $\begin{array}{l}\text { DSE: Improvement by } \geq 1 \text { grade in } \\
\text { WMS in segments abnormal at rest } \\
\text { PET-18 FDG: Tetrofosmin uptake } \leq 70 \% \\
+ \text { a better preserved }{ }^{18} \mathrm{FDG} \text { uptake } \\
\left({ }^{18} \mathrm{FDG} \text {-tetrofosmin uptake }>20 \%\right)\end{array}$ & PSSR & $\begin{array}{l}\text { Viability: } \uparrow \text { PSSR vs } \\
\text { unchanged PSSR for } \\
\text { non-viable segments }\end{array}$ & $\begin{array}{l}\text { AUC for PSSR for prediction of scar was } \\
0.89 \text { ( } 95 \% \text { CI } 0.88 \text { to } 0.90 \text { ) } \\
\text { Sensitivity and specificity of PSSR } 83 \% \\
\text { +84\% respectively vs } 75 \% \text { and } 63 \% \text { for } \\
\text { WMS }\end{array}$ \\
\hline Hanekom et $a l^{15}$ & 55 & TDI & $\begin{array}{l}\text { Previous myocardial infarction; } \\
\text { mean LVEF } 36 \pm 8 \%\end{array}$ & $\begin{array}{l}\text { Regional (WMS) and global ( } \geq 5 \% \text { 个in } \\
\text { LVEF) recovery in LV function on TTE } 9 \\
\text { months post-revascularisation }\end{array}$ & $\begin{array}{l}\mathrm{SR}, \Delta \mathrm{SR}, \mathrm{SS} \text { (end-systolic), } \\
\Delta \mathrm{SS}, \mathrm{PSS}, \mathrm{PSI}, \Delta \mathrm{PSI}, \\
\text { timing parameters }\end{array}$ & $\begin{array}{l}\text { Scar: } \downarrow S R, \downarrow \Delta S R, \downarrow S S, \\
\downarrow \Delta S S, \uparrow \text { timing } \\
\text { parameters }\end{array}$ & $\begin{array}{l}\text { Sensitivity and specificity of TDI } \\
\text { magnitude parameters (highest } 80 \% \text { for } \\
\Delta \text { SR) better than WMS (73\%) but similar } \\
\text { specificity ( } 77 \% \text { ); WMS+TDI (low dose SR } \\
+\Delta \text { SR) sensitivity } 82 \% \text { and specificity } \\
80 \% \text {; AUC } 0.88\end{array}$ \\
\hline Fujimoto et $a l^{18}$ & 48 & TDI & $\begin{array}{l}\text { Previous myocardial infarction } \\
\text { with 'decrease in contractile } \\
\text { myocardium but no necrosis' in } \\
\text { the territory supplied by the } \\
\text { culprit artery } \\
\text { Group } 1(\mathrm{n}=38) \text { : DSE+coronary } \\
\text { angiography } \\
\text { Group } 2(\mathrm{n}=10) \text { DSE before } \\
\text { +after PCI }\end{array}$ & $\begin{array}{l}\text { DSE: Uniphasic (sustained improvement } \\
\text { in WMS at peak stress) or biphasic } \\
\text { (improvement at low dose followed by } \\
\text { dis-improvement at peak dose) response } \\
\text { Group } 2 \text { patients: Improvement in } \\
\text { resting WMS by } \geq 1 \text { grade in } \geq 2 \\
\text { segments }\end{array}$ & $\begin{array}{l}\text { Total strain (TS), PSS, PSI, } \\
\text { L/TS ratio (ratio of systolic } \\
\text { lengthening to the sum of } \\
\text { end- and post-systolic } \\
\text { shortening) }\end{array}$ & $\begin{array}{l}\text { Viability: Peak stress PSI } \\
\geq 0.25 \text { in } 80 \% \text { of viable } \\
\text { segments } \\
\text { Peak stress L/TS ratio }>0 \\
\text { in } 57 \% \text { of viable } \\
\text { segments }\end{array}$ & $\begin{array}{l}\text { AUC of L/TS ratio to predict functional } \\
\text { recovery was } 0.89 \text { vs } 0.78 \text { for WMS, } \\
\text { p }<0.05 \\
\text { L/TS ratio } 84 \% \text { sensitivity and } 79 \% \\
\text { specificity vs } 86 \% \text { sensitivity and } 71 \% \\
\text { specificity for WMS }\end{array}$ \\
\hline Bansal et $a l^{16}$ & 55 & $\begin{array}{l}\text { TDI } \\
\text { STE }\end{array}$ & Known CAD+LVEF $<45 \%$ & $\begin{array}{l}\text { Improvement in resting wall motion (per } \\
\text { segment) on TTE } 9 \text { months } \\
\text { post-revascularisation }\end{array}$ & $\begin{array}{l}\text { TDI: PSSR and SS } \\
\text { (end-systolic) } \\
\text { STE: longitudinal, } \\
\text { circumferential and radial } \\
\text { strain and strain rate (LSS/ } \\
\text { LSR, CSS/CSR, RS/RSR) }\end{array}$ & $\begin{array}{l}\text { Viability: STE: } \uparrow \text { strain in } \\
\text { all } 3 \text { directions and } \uparrow L S R \\
\text { +CSR at rest; } \uparrow L S S \text { and } \\
\text { CSS/CSR at low dose } \\
\text { TDI: } \uparrow P S S R+S S \text { at rest } \\
\text { and low dose }\end{array}$ & $\begin{array}{l}\text { PSSR+SS at low dose and CSS at rest and } \\
\text { low dose only independent predictors of } \\
\text { LV functional recovery } \\
\text { PSSR+SS showed incremental value over } \\
\text { WMS (AUC } 0.79,0.79 \text { and } 0.74 \text {, } \\
\text { respectively). }\end{array}$ \\
\hline Rosner et $a l^{19}$ & 72 & TDI & $\begin{array}{l}\mathrm{N}=57 \text { patients scheduled for } \\
\text { CABG (normal and moderately } \\
\text { reduced LVEF; mean } 49 \% \text { ) } \\
\text { +undergoing pre-op MRI } \\
\mathrm{N}=15 \text { healthy controls }\end{array}$ & $\begin{array}{l}\text { TTE: Difference in ET strain } \geq 4.4 \% \\
\text { between pre- and } 8-10 \text { months } \\
\text { post-CABG resting TTE } \\
\text { MRI: LGE }<50 \%\end{array}$ & $\begin{array}{l}\text { SS (peak/ET), mean SSR, } \\
\text { PSS, PSI, } \Delta S S, \Delta S R\end{array}$ & $\begin{array}{l}\text { Viability: } \triangle S S \\
\text { significantly identified } \\
\text { both hypokinetic and } \\
\text { akinetic segments } \\
\text { improving after CABG } \\
\text { Peak SS+SR, PSS, } \triangle S R \\
\text { significantly identified } \\
\text { akinetic segments } \\
\text { improving after CABG }\end{array}$ & $\begin{array}{l}\text { Sum of pre-op DSE SS increment and } \\
\text { resting SS (had the highest correlation } \\
\text { coefficient for strain defined viability } \\
(R=0.61, p<0.001) \text { ) } \\
\text { AUC for DSE SS increment was } 0.79\end{array}$ \\
\hline
\end{tabular}

*Indicates response of parameters at low dose stress unless indicated.

tIndicates predictive value of peak dose stress parameters unless indicated.

AUC, area under the curve; CABG, coronary artery bypass grafting; CAD, coronary artery disease; $\mathrm{DSE}$, dobutamine stress echocardiography; $\mathrm{ET}$, ejection time; $\mathrm{LGE}$, late gadolinium enhancement; $\mathrm{PCI}$, percutaneous coronary intervention; $\mathrm{PET}-{ }^{18} \mathrm{FDG}$,

positron emission tomography using ${ }^{18}$ F-flurodeoxyglucose; PSI, post-systolic shortening index; PSS, post-systolic strain; PSSR, peak systolic strain rate; SPECT, single photon emission CT; SR, strain rate; SS, systolic strain; STE, speckle tracking

echocardiography; TDI, tissue Doppler imaging; TTE, transthoracic echocardiography; WMS, wall motion scoring; WMSI; wall motion score index. 


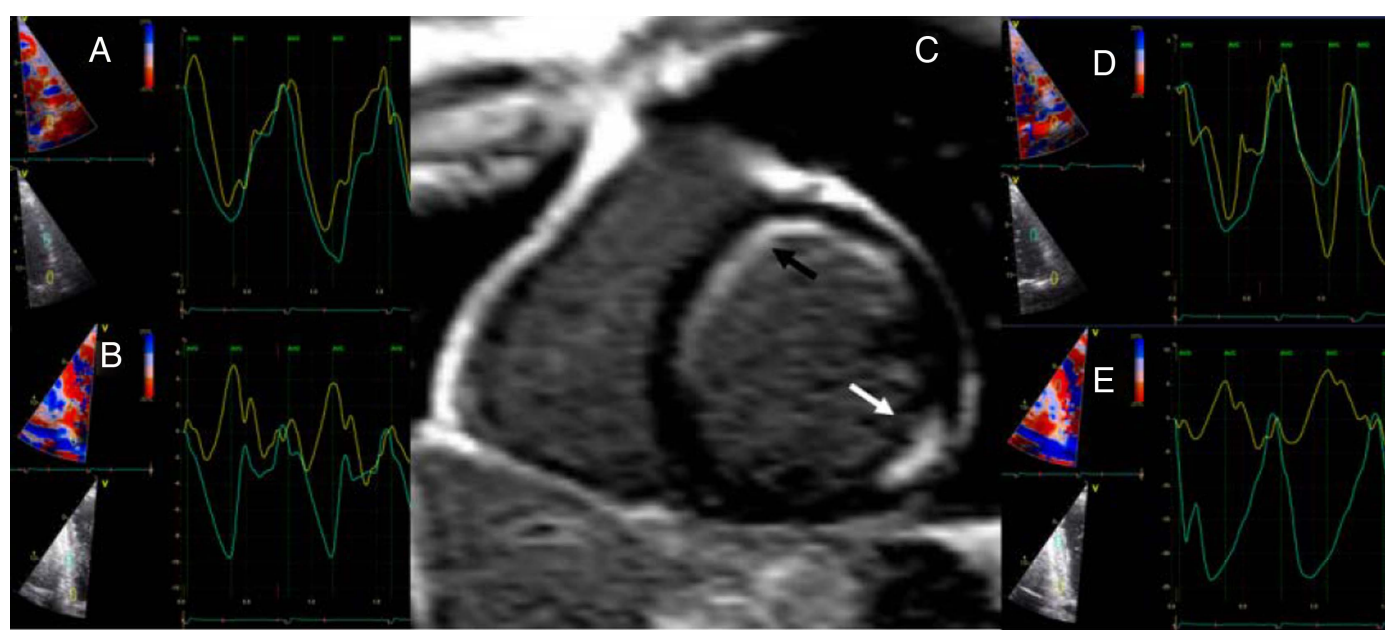

Figure 5 Assessment of myocardial viability with dobutamine stress tissue Doppler imaging (TDI) derived strain. (A) Time-strain curves of the basal and mid anterior segments at baseline. The peak systolic longitudinal strain of the anterobasal and antero-mid segments are $-9.6 \%$ and $-10.8 \%$, respectively. (B) The baseline time-strain curves of the basal and mid posterior segments show a peak systolic longitudinal strain of $-2 \%$ and $-9.8 \%$, respectively. (C) Delayed contrast enhanced magnetic resonance shows a transmural scar posterobasal (white arrow) and subendocardial scar of the basal segments of the septal, anteroseptal and anterior walls (black arrow). During low dose dobutamine stress echocardiography,

(D) TDI derived time-strain curves show improvement in longitudinal strain of the anterior segments (to $-14.5 \%$ and $-15.1 \%$, respectively) and

(E) infero-mid segment (to $-24.6 \%$ ), whereas the inferobasal segment remains unchanged.

prediction of viability in 55 patients with ischaemic LV dysfunction, Bansal et $a l^{16}$ found that longitudinal strain and strain rate at low dose dobutamine as well as resting and low dose circumferential strain predicted functional myocardial recovery independent of wall motion analysis. The finding that resting circumferential strain-acting as a differentiator between subendocardial and transmural infarcts-correlated with viability supports the potential role of differential sublayer mechanics in identifying reversible or irreversible dysfunctional myocardium. These results were complimented by a study of 80 patients with chronic ischaemic LV

\section{You can get CPD/CME credits for Education in Heart}

Education in Heart articles are accredited by both the UK Royal College of Physicians (London) and the European Board for Accreditation in Cardiologyyou need to answer the accompanying multiple choice questions (MCQs). To access the questions, click on BMJ Learning: Take this module on BMJ Learning from the content box at the top right and bottom left of the online article. For more information please go to: http://heart.bmj.com/misc/education. $\mathrm{dtl}$

- RCP credits: Log your activity in your CPD diary online (http://www. rcplondon.ac.uk/members/CPDdiary/index.asp)—pass mark is $80 \%$.

- EBAC credits: Print out and retain the BMJ Learning certificate once you have completed the MCQs-pass mark is $60 \%$. EBAC/ EACCME Credits can now be converted to AMA PRA Category 1 CME Credits and are recognised by all National Accreditation Authorities in Europe (http://www.ebac-cme. org/newsite/?hit=men02).

Please note: The MCQs are hosted on BMJ Learning-the best available learning website for medical professionals from the BMJ Group. If prompted, subscribers must sign into Heart with their journal's username and password. All users must also complete a one-time registration on BMJ Learning and subsequently log in (with a BMJ Learning username and password) on every visit. dysfunction undergoing contrast enhanced MRI to define transmurality of infarction alongside rest stage STE strain imaging in multiple directions and conventional DSE imaging with wall motion analysis. Lower circumferential strain and strain rate at rest were found in transmural infarction compared to subendocardial or non-transmural infarcts, while radial and longitudinal values did not differ significantly. Wall motion analysis by DSE could not identify subendocardial infarction. ${ }^{\text {w17 }}$ These studies reflect that outer layer function, as assessed by STE during DSE, is more likely to be affected in transmural infarction, and differential analysis of each sublayer-as is possible with STE derived deformation analysis-may become the optimal method for viability assessment.

Overall, given the importance of accurately demonstrating myocardial viability in optimising therapy and defining prognosis in patients with ischaemic myocardial dysfunction-even in the post-STITCH era-quantitative assessment of contractile reserve on DSE using novel myocardial mechanics is an exciting and clinically relevant application of these techniques.

\section{FUTURE DIRECTIONS}

In addition to quantitative analysis using deformation imaging, other exciting developments in advanced imaging techniques also hold considerable promise for improving the sensitivity and/or specificity of stress echocardiography. Myocardial contrast perfusion imaging (MCE) also targets the identification of ischaemia before the development of regional wall motion abnormalities using contrast agents to assess coronary perfusion deficits. The timing of contrast replenishment of a vascular bed has been previously shown to identify the degree of coronary stenosis. ${ }^{\text {w18 }}$ Recently, a 
prospective, randomised, controlled trial of realtime MCE versus conventional stress echocardiography in 2014 intermediate and high risk patients followed up for a median of 2.6 years has confirmed improved detection of CAD and more frequent need for revascularisation in the MCE group. ${ }^{20}$

Real-time volumetric 3D echocardiography during stress imaging can also offer significant advantages over standard 2D stress echocardiography, including shortened acquisition time due to the possibility of a single transducer location and elimination of apical foreshortening, thereby improving detection of apical wall motion abnormalities. Currently, accuracy rates of 3D pharmacological stress imaging remain comparable to that of 2D imaging. ${ }^{\text {19 }}$ However, further evolutions in technology-including improved frame rate and single beat image acquisition-are likely to advance the feasibility and accuracy of this modality in the near future.

In summary, although DSE is a well validated and cost effective diagnostic and prognostic tool, potential limitations surrounding image quality and reliance on expert observers may challenge the diagnostic accuracy of DSE for the detection of ischaemia and/or viability. In addition to established techniques such as contrast opacification to improve visualisation, the advent of quantitative techniques such as deformation imaging may improve the reliability and reproducibility of stress echocardiography by permitting quantification of regional myocardial function, thereby reducing dependence on expert observers. Deformation imaging derived by either TDI or STE methods can feasibly be integrated into DSE protocols aimed at detecting the presence of CAD and/or stress induced ischaemia, as well as stunned, hibernating or scarred myocardium.

Competing interests In compliance with EBAC/EACCME guidelines, all authors participating in Education in Heart have disclosed potential conflicts of interest that might cause a bias in the article. The department of cardiology has received research grants from Medtronic, Biotronik, Boston Scientific, St Jude Medical, Lantheus Medical Imaging, and GE Healthcare. V Delgado has received consulting fees from Medtronic and St Jude Medical. The other authors have no competing interests to declare.

Contributors All authors contributed to this paper.

Provenance and peer review Commissioned; externally peer reviewed.

\section{REFERENCES}

1 Pellikka PA, Nagueh SF, Elhendy AA, et al. American Society of Echocardiography recommendations for performance, interpretation, and application of stress echocardiography. J Am Soc Echocardiogr 2007;20:1021-41.

2 Senior R, Monaghan M, Becher $H$, et al. Stress echocardiography for the diagnosis and risk stratification of patients with suspected or known coronary artery disease: a critical appraisal. Supported by the British Society of Echocardiography. Heart 2005;91:427-36.

3 Plana JC, Mikati IA, Dokainish H, et al. A randomized cross-over study for evaluation of the effect of image optimization with contrast on the diagnostic accuracy of dobutamine echocardiography in coronary artery disease. The OPTIMIZE trial. JACC Cardiovasc Imaging 2008;1:145-52.

- Landmark trial on the impact of the use of contrast on the diagnostic accuracy of DSE to detect significant CAD.
4 Sicari R, Nihoyannopoulos P, Evangelista A, et al. Stress echocardiography expert consensus statement-executive summary: European Association of Echocardiography (EAE) (a registered branch of the ESC). Eur Heart J 2009:30:278-89.

5 Senior R, Becher H, Monaghan M, et al. Contrast echocardiography: evidence-based recommendations by European Association of Echocardiography. Eur J Echocardiogr 2009;10:194-212.

6 Blessberger $\mathrm{H}$, Binder T. Two dimensional speckle tracking echocardiography: clinical applications. Heart 2010;96:2032-40.

- Comprehensive review article on the basic principles and clinical applications of STE.

7 Bijnens B, Claus P, Weidemann F, et al. Investigating cardiac function using motion and deformation analysis in the setting of coronary artery disease. Circulation 2007;116:2453-64.

- Landmark study on TDI myocardial deformation in patients with CAD.

8 Voigt JU, Exner B, Schmiedehausen K, et al. Strain-rate imaging during dobutamine stress echocardiography provides objective evidence of inducible ischemia. Circulation 2003;107: 2120-6.

- First head to head comparison between TDI derived strain and myocardial perfusion single photon emission $\mathrm{CT}$ to detect significant CAD.

9 Ingul CB, Stoylen A, Slordahl SA, et al. Automated analysis of myocardial deformation at dobutamine stress echocardiography: an angiographic validation. J Am Coll Cardiol 2007;49:1651-9.

$10 \mathrm{Ng} \mathrm{AC}$, Sitges M, Pham PN, et al. Incremental value of 2-dimensional speckle tracking strain imaging to wall motion analysis for detection of coronary artery disease in patients undergoing dobutamine stress echocardiography. Am Heart $\rfloor$ 2009; 158:836-44

11 Hanekom L, Cho GY, Leano R, et al. Comparison of two-dimensional speckle and tissue Doppler strain measurement during dobutamine stress echocardiography: an angiographic correlation. Eur Heart J 2007;28:1765-72.

- First comparison between TDI and speckle tracking derived strain as adjunctives to DSE for detection of significant CAD.

12 Weidemann $F$, Jung $P$, Hoyer $C$, et al. Assessment of the contractile reserve in patients with intermediate coronary lesions: a strain rate imaging study validated by invasive myocardial fractional flow reserve. Eur Heart J 2007;28:1425-32.

13 Yu Y, Villarraga HR, Saleh HK, et al. Can ischemia and dyssynchrony be detected during early stages of dobutamine stress echocardiography by 2-dimensional speckle tracking echocardiography? Int I Cardiovasc Imaging 2013; 29:95-102.

14 Joyce $E$, Leong DP, Hoogslag GE, et al. Left ventricular twist during dobutamine stress echocardiography after acute myocardial infarction: association with reverse remodeling. Int I Cardiovasc Imaging 2014;30:313-22.

15 Hanekom $L$, Jenkins $C$, Jeffries $L$, et al. Incremental value of strain rate analysis as an adjunct to wall-motion scoring for assessment of myocardial viability by dobutamine echocardiography: a follow-up study after revascularization. Circulation 2005;112:3892-900.

16 Bansal $M$, Jeffriess $L$, Leano $R$, et al. Assessment of myocardial viability at dobutamine echocardiography by deformation analysis using tissue velocity and speckle-tracking. JACC CardiovasC Imaging 2010;3:121-31.

17 Hoffmann R, Altiok E, Nowak B, et al. Strain rate measurement by Doppler echocardiography allows improved assessment of myocardial viability in patients with depressed left ventricular function. J Am Coll Cardiol 2002;39:443-9.

18 Fujimoto $\mathrm{H}$, Honma $\mathrm{H}$, Ohno T, et al. Longitudinal Doppler strain measurement for assessment of damaged and/or hibernating myocardium by dobutamine stress echocardiography in patients with old myocardial infarction. J Cardiol 2010;55:309-16.

19 Rosner A, Avenarius D, Malm S, et al. Persistent dysfunction of viable myocardium after revascularization in chronic ischaemic heart disease: implications for dobutamine stress echocardiography with longitudinal systolic strain and strain rate measurements. Eur Heart I Cardiovasc Imaging 2012;13:745-55.

20 Porter TR, Smith LM, Wu J, et al. Patient outcome following 2 different stress imaging approaches: a prospective randomized comparison. J Am Coll Cardiol 2013;61:2446-55.

- Large prospective trial comparing the diagnostic and prognostic value of stress real-time myocardial contrast echocardiography and conventional stress echocardiography. 